\title{
Efficiency of Diaveridine and Sulphaquinoxaline with and without vitamin $A$ and $K$ to treat the broiler caecal coccidiosis
}

\author{
Khalid Muhammad ${ }^{1}$, Shabnam Razzaq Khan ${ }^{2}$, Nazeer Hussain
} Kalhoro $^{3}$, Shakeeb Ullah ${ }^{1}$, Muhammad Shuaib Khan ${ }^{1}$, Muhammad Inamullah Malik ${ }^{*}$, Adnan Amin ${ }^{4}$, Ali Zaman ${ }^{1}$, Ambrina Tariq ${ }^{5}$, Mumtaz Ali Khan ${ }^{6}$, Atiq ur Rehman ${ }^{1}$, Ayesha Haleem Shah ${ }^{7}$, Naimatullah ${ }^{1}$ and Saqib Ali Rustam ${ }^{1}$

1. Faculty of Veterinary and Animal Sciences, Gomal University, D.I. Khan-Pakistan

2. Institute of research and education, Gomal University, D.I. Khan-Pakistan

3. Director General Sindh Institute of Animal Health, Karachi-Pakistan

4. Department of Pharmacognosy, Faculty of Pharmacy, Gomal University, D.I. Khan-Pakistan

5. Civil Veterinary Hospital, D.I. Khan-Pakistan

6. Department of clinical Medicine and Surgery, University of Veterinary and Animal Sciences, Lahore-

Pakistan

7. Department of Biological Sciences, Gomal University, D.I. Khan-Pakistan

*Corresponding author's email: malikinamgu@gmail.com

Citation

Khalid Muhammad, Shabnam Razzaq Khan, Nazeer Hussain Kalhoro, Shakeeb Ullah, Muhammad Shuaib Khan, Muhammad Inamullah Malik, Adnan Amin, Ali Zaman, Ambrina Tariq, Mumtaz Ali Khan, Atiq ur Rehman, Ayesha Haleem Shah, Naimatullah and Saqib Ali Rustam. Efficiency of Diaveridine and Sulphaquinoxaline with and without vitamin $\mathrm{A}$ and $\mathrm{K}$ to treat the broiler caecal coccidiosis. Pure and Applied Biology. Vol. 8, Issue 2, pp1592-1599. http://dx.doi.org/10.19045/bspab.2019.80101

\begin{tabular}{llll}
\hline \hline Received: 26/02/2019 & Revised: 20/05/2019 & Accepted: 25/05/2019 & Online First: 03/06/2019 \\
\hline \hline
\end{tabular}

\section{Abstract}

The study was planned to determine the efficiency of Diaveridine and sulphaquinoxaline with and without supplementation of vitamin $\mathrm{A}$ and $\mathrm{K}$ for the treatment of Broiler coccidiosis. Birds were divided into four groups A, B, C and D containing 50 birds each. Group A served as negative control while group B, C and D were induced with infections and served as experimental groups. Birds of Group B were not treated with any anticoccidial drug therefore oocyst count per gram of faeces was more than other groups, morbidity and mortality rates were $92 \%$ and $28 \%$ respectively while weight gain was less than other groups. Group $\mathrm{C}$ was treated with anticoccidial drug e.g darvisul liquid, coccidial oocyst count was more than D and less than B per gram faeces, morbidity and $4 \%$ mortality rates were $16 \%$ and $4 \%$ respectively while weight gain was less than D and more than B. Group D was treated with anticoccidial drug e.g coccidak powder, coccidial oocyst count was lesser. Morbidity and mortality rates were $8 \%$ and $0 \%$ respectively while weight gain was more than group $\mathrm{C}$ and $\mathrm{B}$. It indicated that diaveridine and sulphaquinoxaline are useful to treat the broiler coccidiosis with both vitamins than without their supplementation.

Keywords: Anti coccidial; Broiler coccidiosis; Efficacy; Treatment

\section{Introduction}

The production of poultry is adversely affected by the coccidiosis in poultry because it has more economic losses with high morbidity and mortality rates and also decreases the weight gain of birds and 
renders huge economic losses in terms of prevention, treatment and control of diseases [1-3]. This infection is caused by a parasite Eimeria tenella in the poultry. The parasites grow and multiply in the intestinal epithelium of chickens and oocytes are spread out in the faeces $[4,5]$. The parasites are found in carrier and diseased chickens and also naturally present in the environment where the chickens are reared for long period [6]. Due to rearing of poultry birds in concentrated environment, coccidiosis incidence is higher throughout the world [9-11]. According to Williams [12] in poultry birds world widely millions of US dollars are spent to overcome this infection. In this regard many anticoccidial drugs are used within water or feed. Best managemental practices also have an important role in prevention of this infection [2, 13, 14]. These drugs are known as Anticoccidials, which include ethopabate, amprolium, sulphonamides, ionophores, clopidol and quinolones. These drugs are capable to treat coccidiosis, also helpful for increase in FCR and weight gain of poultry birds that's why used on the basis of this capability. These drugs do not compensate the immune system of birds. Sulphonamides are the broad spectrum drugs used against this infection but these drugs are coccidiostatic in nature. These drugs are used for the prevention \& treatment of coccidiosis in poultry e.g sulphadimethoxine, sulphaquinoxaline, sulphadimidine sulphaguanidine, and sulphanitran since 1939.

The combination of diaveridine $\&$ sulphaquinoxaline is effectively used against coccidial infection in poultry [1518]. Vitamin $A$ and $K$ decreases the adverse effects of infection and increase weight gain and recovery rate against coccidiosis [19-26]. Internal hemorrhages of muscles and other organs in bird are prevented with the addition of Vitamin $\mathrm{K}$ in water, [27-32]. The focus of current work was on the study of effectiveness of diaveridine and sulphaquinoxaline with $\&$ without use of Vitamin-A and $\mathrm{K}$ supplement. Its effects on the general body condition, oocyst count in faeces, mortality, morbidity rate and weight gain. To compare the therapeutic value of coccidak powder and Darvisul liquid for the treatment of poultry coccidiosis. Current study provides further scientific information for the treatment and prevention of this disease in poultry.

\section{Materials and methods}

Caecal coccidiosis was induced artificially in broiler birds \& for treatment of this disease anticoccidial drugs were used and their effects on the oocyst count in faeces, weight gain, morbidity and mortality rates, clinical and postmortem findings were observed \& recorded. The infective oocytes were acquired from Veterinary Research Institute, Peshawar. Then further processing of these infected caeca was done for the identification \& isolation of coccidial oocysts in Faculty of Veterinary and Animal Sciences, Gomal University, Dera Ismail Khan [33].

Birds of age 200 days were bought from Hi-tech hatchery and raised for 52 days. Then equally distributed into 4 groups named as A, B, C and D shown in table 1 and each group had 50 broiler birds, total 200.

Table 1. Arrangement of groups

\begin{tabular}{|c|c|}
\hline \multicolumn{2}{|c|}{ GROUPS } \\
\hline A & Uninfected and unmedicated control group \\
\hline B & Infected and unmedicated control group \\
\hline C & Infected and medicated with darvisul liquid \\
\hline D & Infected and medicated with coccidak powder \\
\hline
\end{tabular}




\section{Vaccination of birds}

Vaccination of all birds was done with ND and IBD vaccine.

\section{Coccidial oocyst count in faeces}

McMaster counting method was adopted to calculate the coccidial oocyst per gram of faeces. Coccidial infection was firstly induced on day 22 and coccidial oocysts were firstly counted on day 25 . Till the end of the study i.e. $52^{\text {nd }}$ day, on each $3^{\text {rd }}$ day in one gram of faeces coccidial oocysts were counted.

After inducing the infection, oocyst count in one gram of faeces of birds of all 4 groups were recorded.

Until the end of the study body weight gain was determined by weighing the birds of each group on weekly basis.

After inducing the infection clinical findings were recorded and observed.

Until the end of experimental study, morbidity and mortality rates were calculated.

Postmortem examination of dead birds was performed to evaluate the gross pathology of birds.

\section{Experimental data}

Statistical analysis was done to evaluate the fluctuation in weight gain of birds and oocyst count per gram of faeces.

\section{Results}

\section{Oocyst count in faeces}

Birds belonging to group A were not containing oocysts of Emeria tenella in faeces. On day $25^{\text {th }}$, in faeces of each bird of group B the oocysts were seen \& on day $37^{\text {th }}$, this count was increased in number upto 140000 and 8 mortalities occured during this period. On day 52 the count of oocyst in faeces slowly decreased to 13000 $\&$ mortality of 4 more occurred.

After three days of each infection, darvisul liquid was used to treat infected Group C birds for 3 days then plain water was given for 2 days and for two more days same treatment was repeated. On day 2 the highest oocyst number was 8050 while on day 52 this count decreases to 200 . Oocyst count of the group $\mathrm{C}$ was lesser than B.
After three days of infection, coccidak powder was used to treat the infected birds of D group \& treatment interval was same as done with group C. On day 25 the highest oocyst count was 9400 while on day 40 this count was decreased to 700 and then upto the end of study result was zero. So faecal oocyst count of the birds of group D were less than the group B and C. It showed that the coccidak powder had better therapeutic effect relative to darvisul liquid.

\section{Body weight gain}

The average body weight gain of group A, $\mathrm{B}, \mathrm{C}$ and $\mathrm{D}$ was $40,41,41 \& 39 \mathrm{gm}$ respectively that improved to 1783 , $1281,1544 \& 1650$ grams at the day 52 respectively. Results showed that group A achieved the highest weights gain because it was a disease free control group. The group A, D, C and B placed in the $1^{\text {st }}, 2^{\text {nd }}$, $3^{\text {rd }}$ and $4^{\text {th }}$ position respectively in sense of weight gain while B group placed at lowest level.

\section{Clinical findings}

Each bird of every group was daily observed during the whole study and Group A was found sound in all aspects. Infected birds of the group B, showed the following clinical signs as dull, lethargic, depressed, inactive, restless and exhausted. Their feathers were bothered and feed \& water consumption became low. The birds had droopy wings, colour of combs \& wattles become whitish. In diseased birds bloody diarrhea was also seen that resulted in anemic condition. Moreover, health status of those birds is not good and growth was retarded.

The diseased birds of group C showed clinical signs which were more severe than group D but less severe than group B. but the diseased birds of group D showed mild clinical signs as compare to group B and group C.

\section{Morbidity}

The morbidity rate was recorded as $0 \%$, $92 \%, 16 \%$ and $8 \%$ respectively for groups $\mathrm{A}, \mathrm{B}, \mathrm{C}$ and $\mathrm{D}$ (Table 2). 
Mortality

The mortality number of group A, B, C and D was zero, 14, 2 and zero respectively till the end of experimental study (Table 2).

Table 2. Group wise mortality and Morbidity rates on the basis of days

\begin{tabular}{|c|c|c|c|c|c|c|c|c|c|c|}
\hline Groups & Days & $1-7$ & $8-15$ & $16-23$ & $\begin{array}{c}24- \\
31\end{array}$ & $\begin{array}{c}32- \\
39\end{array}$ & $\begin{array}{c}40- \\
47\end{array}$ & $\begin{array}{c}48- \\
52\end{array}$ & total & \%age \\
\hline A & Mortality & 0 & 0 & 0 & 0 & 0 & 0 & 0 & 0 & 0 \\
\hline A & Morbidity & 0 & 0 & 0 & 0 & 0 & 0 & 0 & 0 & 0 \\
\hline B & Mortality & 0 & 0 & 0 & 1 & 6 & 5 & 2 & 14 & 28 \\
\hline B & Morbidity & 0 & 0 & 12 & 15 & 13 & 6 & 0 & 46 & 92 \\
\hline C & Mortality & 0 & 0 & 0 & 1 & 1 & 0 & 0 & 2 & 4 \\
\hline C & Morbidity & 0 & 0 & 3 & 2 & 3 & 0 & 0 & 8 & 16 \\
\hline D & Mortality & 0 & 0 & 0 & 0 & 0 & 0 & 0 & 0 & 0 \\
\hline D & Morbidity & 0 & 0 & 3 & 1 & 0 & 0 & 0 & 4 & 8 \\
\hline
\end{tabular}

\section{Postmortem findings}

Following lesions were seen and recorded on the postmortem examination of the dead in various organs of birds.

Wattles; it had pale color.

Combs; it had pale color

Carcasses; the carcasses of dead birds were seen emaciated.

The Caeca; The colour of caeca were red and were hemorrhagic and inflamed.

Blood in faeces were recorded

Enlarged liver and spleen were seen.

The lungs' colour was pale.

Pericardium; Pericardium of dead birds had hemorrhages.

Anemia; Due to loss of blood internal organs were anemic and color became pale.

Dehydration; Dehydration of Internal organs was also recorded.

\section{Discussion}

The current work was done to find out the efficacy of diaveridine and sulphaquinoxaline sodium by using in combination with and without vit $\mathrm{A}$ and $\mathrm{K}$ supplements to treat caecal coccidiosis in poultry birds. 40,000 sporulated oocysts Emeria tenella were orally given to the birds of group B, C and D on $22^{\text {nd }}$ and $32^{\text {nd }}$ days of their age. The birds of group A were in control group and kept as uninfected and unmedicated.
Coccidian oocyst count

Until the end of the current study the coccidial oocyst in faeces of birds of group A were not recorded. This result was same as the results [34] stated that the birds of healthy, unmedicated, control group had highest weight gain and oocysts count in one gram of faeces was zero.

In group $\mathrm{B}$, on $3^{\text {rd }}$ day of infection $\left(25^{\text {th }}\right.$ day), this group had 7200 oocyst count in one gram of faeces, but on day 37 this count increases upto 140000 and then this level decreased slowly and reaches to 13000 on day 52, results as [35]. The results of this study is also same as [37] which stated that we should understand the intensity of disease by oocyst shed in faeces and mortality caused by it and by $[4,38,39]$ stated that mortality is high in infected groups and some information which is related to this have also been reported by $[4,38]$.

In group $\mathrm{C}$, on day $25^{\text {th }}$, the highest oocyst count in one gram faeces was 8050 which decreased to 200 on the day $52^{\text {nd }}$. The studies of $[16,40]$ are approximately same as with current study stated that the very effective treatment and control of avian coccidiosis is the use of sulphaquinoxaline with diaveridine. The results of the current study are also similar with the conclusions of $[1,15,41,42]$, that caecal coccidiosis 
effectively treated by using sulphaquinoxaline combined with diaveridine.

In group $\mathrm{D}$, on day $25^{\text {th }}$ the oocyst count in one gram of faeces was 9400 and then decreases to 700 on day 40 and later on $52^{\text {nd }}$ days the count was zero. The conclusions of $[16,40]$, are similar with current study. The conclusions of [27] are also related with current study in which we observed the highest mortality in infected groups. Moreover, he [27] stated that we effectively control the poultry coccidiosis by using vitamin $\mathrm{K}$ with sulpha drugs. The results of current study are also similar with the studies of $[15,19$, $21,23]$ stated that the recovery from coccidiosis increased by use of vitamin A and vitamin $\mathrm{K}$ and faecal oocyst count also decreases by it.

In the group $\mathrm{C}$ and $\mathrm{D}$, faecal oocyst count was low as compare to B group, so it shows the good therapeutic effect of drugs to treat the avian coccidiosis. The use of sulphaquinoxaline with diaveridine decreases oocyst count in one gram of faeces. Group D this count was low than $\mathrm{C}$, because the anticoccidial drugs combinely used with vitamin A and K.

\section{Morbidity and mortality}

The birds of group A were healthy so no morbidity and mortality was recorded. These conclusions are in similar with [43], which stated that in uninfected group no morbidity and mortality was seen. In the birds of group B, highest morbidity ( $92 \%$ ) and mortality $(28 \%)$ were seen than other groups $\mathrm{C}$ and $\mathrm{D}$. These conclusions are similar with [43, 44], which stated that morbidity rate was $100 \%$ and mortality rate was $38 \%$ in infected and unmedicated birds. In the birds of group C, $16 \%$ morbidity and $04 \%$ mortality was recorded. This conclusion is similar with $[1,14,42]$, which stated that sulphaquinoxaline is very effective to treat and prevent caecal coccidiosis. In the birds of group D, $08 \%$ morbidity and zero mortality was recorded. These conclusions are similar with [19-21], which stated that mortality and morbidity was lesser in birds of that group which were treated by anticoccidial drugs in combination with vitamin A and vitamin $\mathrm{k}$. In the birds of group $\mathrm{D}$, the rate of morbidity and mortality was less than group $\mathrm{C}$, the reason behind it may be the use anticoccidial drugs in combination with vitamin $\mathrm{A}$ and vitamin $\mathrm{K}$.

\section{Postmortem lesions}

The following Postmortem lesions in dead birds were seen during postmortem, inflammation of intestine \& hemorrhages on caecal wall. The carcasses of dead birds were thin and anemic. The internal organs of birds were pale in color and dehydrated. [45] saw severe enteritis, hemorrhages on pericardium and enlargement of liver \& spleen upto some extent. [46] did the postmortem examination of infected birds and saw intestines \& other organs were effected. He stated that liver and lungs were pale in color \& dehydrated. [47] Performed the postmortem examination and saw inflammation of the caeca $\&$ also blood in it. [27, 48] observed hemorrhages on caeca \& carcasses were anemic. [49] Recognized infection in both caeca cause blood \& acute infection may effect intestine. [50] Observed blood in caeca \& its wall are thickened \& mucosal surface was eroded and distended cecum with blood. These findings are similar to the current results. Above stated results are harmonious with the current findings.

\section{Clinical signs}

The diseased birds were weak, listless, anemic, depressed, anorexic, lethargic and diarrhea was blood stained \& had drooped feathers \& wings. The color of combs and wattles changed to whitish. Moreover, the birds had slow growth rate \& weight gain decreased. [51] Observed low body weight gain on $7^{\text {th }}$ day of infection. [52] Bloody diarrhea on $4^{\text {th }}$ day of infection. [49] Birds intermittently produced a high-pitched sound \& huddled together \& no feed \& water consumption $\&$ severe attack of coccidiosis cause 
sudden death. [1] states that caecal coccidiosis in poultry caused by Eimeria tenella and effect the health of bird adversely \& if the parasite burden is too high then the disease is severe and if the parasitic load is low cause mild disease. Various researchers declared the above results are similar with the current study.

\section{Body weight gain}

The results showed that group A gain the highest and B had lowest body weight than the other groups. These results are similar with the observation of [34]. [43] Stated that the birds of uninfected control group had highest body weights while the infected group which was unmedicated group had lowest body weight. Weight gain in birds of group D was higher than the birds of group $\mathrm{C}$ because the group $\mathrm{D}$ were medicated with coccidak powder and group $\mathrm{C}$ were treated with darvisul liquid. [1] Recorded that to treat this disease different anticoccidials drugs are used depending on their ability to increase the FCR and body weight. [28] Vitamin A and vitamin $\mathrm{D}$ was given to infected birds which cause high growth and health status become good [25]. The infected birds of one group treated with sulphaquinoxa line in combination with vitamin-A and recorded that the gained increased body weights than the birds of that group which were not treated. [21] Stated that birds gained higher body weight which were supplemented with vitamin $\mathrm{A}$ in their feed. [19] Concluded that the birds of that group which were treated with anticoccidial drugs in combination with vitamin-A and $\mathrm{K}$ supplement gained higher body weight. Various researchers cited above results which are similar to results of current study.

\section{Conclusion}

It was concluded that to reduce the severity of infection Vitamin A \& $\mathrm{K}$ are very important \& help to reduce mortality during infection \& increases the body weight gain. These vitamins are also important for general health of the birds and to control the poultry coccidiosis,
Sulphaquinoxaline and diaveridine have high therapeutic effect along with the supplementation of vitamin A \& K. The use diaveridine and sulphaquinoxaline along with supplement of vitamin A and $\mathrm{K}$ have better results while Darvisul liquid have low therapeutic effect as compare to coccidak powder. By using the coccidak powder we effectively controls the morbidity, mortality of infected birds and it also increases body weight gain in birds.

\section{Authors' contributions}

Conceived and designed the experiments: K Muhammad, NH Kalhoro \& S Ullah, Performed the experiments: K Muhammad, SR Khan \& AH Shah, Analyzed the data: A Amin, Naimatullah \& A Zaman, Contributed reagents/ materials/ analysis tools: MS Khan, MA Khan, SA Rustam \& AU Rehman, Wrote the paper: MI Malik \& A Tariq.

\section{References}

1. Kant V, Singh P, Verma PK, Mehtab IB, Gopal SP \& Gupta V (2013). Anticoccidial drugs used in the poultry. Sci Inter J 261-265.

2. Akhtar M, Hafeez MA \& Haq AU (2005). Immunity against coccidiosis in poultry- A review. Inter $J$ Poult Sci 4(10): 812-817.

3. Qadir AAA, Hashmi HA, Khan MS, Naseem A \& Khurram S (1992). Comparative efficacy of different locally available coccidiostats in the treatment of coccidiosis in broiler chicken. Pak $J$ Livestock Res 2(1-2): 10-13.

4. Jordan FTW (1990). Poultry diseases, $3^{\text {rd }}$ Ed., Baillere Tindal 237-241.

5. Soulsby EJL (1982). Helminths, arthropods and protozoa of domesticated animals. $7^{\text {th }}$ Edit., 630- 44. ELBS, Bailliere Tindal, London.

6. McDougald LR, Saif YM, Barnes HJ, Glisson JR, Fadly AM \& Swayne DE (2003). Diseases of Poultry, $11^{\text {th }}$ edit, (Eds.) Iowa State Press, Blackwell Publishing Company, USA. 974-991.

7. Kelly WR (1986). Veterinary clinical diagnosis, $3^{\text {rd }}$ Edit, Bailliere Tindal: 244 245.

8. Urquhart GM (1987). Veterinary parasitology, IST Ed., ELBS, Longman 
House, Burnt Mills Harlow, England: 256-257.

9. Biggs PM (1982). The world of poultry diseases. Avian Pathol 11: 281-283.

10. Rose ME (1987). Immunity to Eimeria infections. Vet Immunol Immunopathol 17: 333-343.

11. Williams RB (1999). A compartmentalized model for the estimation of the cost of coccidiosis to the world's chicken production industry. Inter J Parasitol 29: 1209-1229.

12. Williams RB (1998). Epidemiological aspects of the use of live anticoccidial vaccines for chickens. Inter J Parasitol 28: 1089-1098.

13. Bhatti BM (1989). Incidence of poultry diseases and their importance in poultry production in Pakistan. Pak Vet J 9(4):194-197.

14. Zhang Q, Ruixue L, Jinjiang Z, Yulong Z, Junchin X \& Zhang W (1995). Test on sulphaquinoxaline sodium against caecal coccidiosis in chicks, 25(10): 30-31.

15. Panda DN, Mishra A, Mishra SC \& Panda BK (1997). Incidence of coccidiosis in broiler in and around Bhubaneswar, Orissa. Ind Vet J 74(5): 430431.

16. Mukherjee J, Guha C \& Mitra SK (1994). Therapeutic efficacy of supercox, diocoxin and zycox against experimental caecal coccidiosis in broiler chicks. Ind Vet J 71(9): 870-873.

17. Long PE (1984). Coccidiosis control past, present and future. Brit Poult Sd 25: 3-18.

18. Clarke ML (1962). A mixture of diaveridine and sulphaquinoxaline as a coccidiostat for poultry-I preliminary studies on efficacy against Eimeria tenella and Eimeria necatrix infection and on toxicity in poultry. Vet Rec 74(31): 845-848.

19. Hameed A (1999). Treatment of experimentally induced coccidiosis and its effect on various blood components in quails. M.Sc. (Hons.) thesis, College of Vet Sci, Lahore, University of Agriculture, Faisalabad.

20. Ghazala N, Mian MS, Afzal M, Khan MS, Rabbani A, Saeed K \& Zaman MS (1990). A study on the effects of vitamins $\mathrm{A}$ and $\mathrm{K}$ on the anticoccidial activity of
ESb3 in broiler chicks. Pak $J$ Sci 39/40: 166-171.

21. Saleem M, Hayat B \& Hayat CS (1984). Effects of different level of vitamin A on coccidiosis in chicks. M.Sc (Hons) thesis, Uni of Agri Faisalabad.

22. Malik MN (1984). Comparative anticoccidial activity of newly introduced coccidiostats against experimental coccidiosis and their effects on growth rate in broiler chickens. MSc. (Hons) thesis, Univ. Agri, Faisalabad, Dept of Parasitology.

23. Otto HS (1979). Avian Coccidiosis. The Merk Veterinary Manual 1128-1133.

24. Ryley JF \& Hardman L (1978). The use of vitamin $\mathrm{K}$ deficient diets in the screening and evaluation of anticoccidial drugs. Parasitol 76: 11-20.

25. Zafar MNK (1976). Effect of vitamin A and coccidiostats against caecal coccidiosis in chickens. M.Sc. Thesis, Univ. Agri. Faisalabad.

26. Davies SFM \& Joyner LP (1963). The effect of dietary vitamin K on severity of coccidial infection in fowl. Parasitol 53: 324.

27. Amal Kumar S (2006). Pathological study of coccidiosis in chick bird. Res $J$ Anim Vet Sci 1(1): 55-56.

28. Shakov SH \& Denovski (1965). Coccidiosis and vitamin levels in chickens-II. Assimilation and exhaustion of vitamins $A$ and $D$ various degrees of infection. Vet. Med. Nawki Sof 2: 403-410.

29. Waldroup PW, Cox DD \& Harm RH (1960). The effect of feeding various level of menadion sodium bisulphate comp. to chick infected with coccidiosis. Poult Sci 39: 1303-1305.

30. Stephans JF \& Tugwell RL (1960). Sources and level of vitamin $\mathrm{K}$ in relation to caecal coccidiosis. Poult Sci 39: 118387.

31. Barnett BO, Richey DJ \& Morgan CD (1957). Hemorrhages in chicks induced by beld. Aminopropinitnle and Sulphaquinoxaline. Poult Sci 36: 11041106.

32. Goldhoft TM \& Wernicoff N (1954). A report on hemorrhagic condition in poultry in USA, World Poult. Congr. Edin Vet Bull 25: 245-247.

33. Ministry of Agriculture, Fisheries science and Food (1998). Manual of 
Veterinary Parasitological Techniques, published by Ministry of Agriculture, Fisheries and Food, U. K: 70-89.

34. Awan AR, Hashmi HA, Sabir M, Maqbool A \& Afzal M (1995). Host reaction to experimentally induced Eimeria infections in broiler chicks. Proc. ${ }^{\text {th }}$ Pak Cong Zool, $15-17^{\text {th }}$ April, at NARK, Islamabad.

35. Ashraf M (1994). The effect of induced coccidiosis on growth and blood parameters in commercial quails. MSc (Hons). Thesis, Uni. Agri. Faisalabad.

36. Tipu MA, Pasha TN \& Ali Z (2002). Comparative efficacy of salinomysin sodium and neem fruit as feed additive anticoccidials in broilers. Inter $J$ Poult Sci 1(4): 91-93.

37. Hein H (1971). Pathogenic effect of Eimeria necatrix in young chickens. Exp Parasit 30: 231-330.

38. Oikewa $\mathrm{H}$, Kawagichi $\mathrm{H} \&$ Isunoda $\mathrm{K}$ (1971). Changes of organ weight and blood components in avian coccidiosis caused by Eimeria tenella and Eimeria acervulina. Jap $J$ Vet Sci 33: 251-259.

39. Younas MK (2001). Oocyst production potential in experimentally infected broiler with Eimeria tenella. M.Sc. (Hons.) thesis, Col Vet Sci Lahore, Uni Agri, Faisalabad.

40. Majumdar P, Guha C \& Pramanik AK (1993). Studies of the comparative efficacy of duocoxin, amadon and IHP$250 \mathrm{C}$ against Eimeria tenella infection in broiler chicks. Ind Vet J 70(6): 501-504.

41. Elmusharaf MA \& Beynen AC (2007). Coccidiosis in poultry with emphasis on alternative anticoccidial treatments, department of nutrition, Faculty of veterinary medicine, Utrecht University, the Netherlands.

42. Campbell WC (2008). History of the discovery of sulphaquinoxaline as a coccidiostat. Parasitol 94(4): 934-945.
43. Ashraf TN, Pasha NA, Mian A \& Hashmi ZA (2002). Comparative efficacy of different additive Anticoccidials in broilers. Inter J Poult Sci 1(6): 185- 187.

44. Razzaq A (1999). A study on the effect of experimentally included coccidiosis on height gain and hematological parameters and its control in quails. M.Sc (Hons) thesis, Col Vet Sci Agri Uni. Faisalabad.

45. Masood F (2000). Comparative efficacy of different prophylactic measures against coccidiosis in broilers. M.Sc. (Hons.) thesis, Col Vet. Sci. Lahore, Uni. Agri, Faisalabad.

46. Afzal MN (2001). Bio control of caecal coccidiosis in broilers. M.Sc. (Hons.) thesis, Col Vet Sci Lahore, Uni. Agri, Faisalabad.

47. Baig MW (2003). A comparison of biological and medicinal control of coccidiosis in broilers under field conditions. M.Sc. (Hons.) Thesis, Uni. Vet Anim. Sci. Lahore.

48. Rashid MI (2006). Comparative efficacy of different prophylactic and curative measures against caecal coccidiosis. MSc. (Hons.) thesis, Uni. Vet Anim Sci Lahore.

49. Conway DP \& McKenzie ME (2007). Poultry coccidiosis, diagnostic and testing procedures, $3^{\text {rd }}$ edit. 2121 state avenue, lowa 50014, USA: 30-32.

50. Amaere A, Netsanet $\mathrm{W} \&$ \& Haileleul $\mathrm{N}$ (2012). Coccidiosis prevailing in parent stocks, a comparative study between growers and adult layers in Kombolcha poultry breeding and multiplication centre, Ethiopia. Glo Vet 8(3): 285-291.

51. Calnek BW, Barnes HJ, Beard CW, Reid WM \& Yoder HW (1991). Diseases of Poultry, 9th Ed., Wolf Pub Ltd London 733-735.

52. Lin $Y$ \& Feng ZG (1993). Pathomorphological studies of chicken experimentally infected with $E$. tenella. Acta Vet Zootech 24(5): 446-451. 